\title{
IMOBILIZAÇÃO DA ENZIMA PEROXIDASE RAIZ FORTE (HRP) APRESENTA DIVERSIFICADAS APLICAÇÕES, EM SUPORTES HÍBRIDOS DE SÍLICA-POLISSACARÍDEO (AMIDO).
}

\author{
$\underline{\text { Ariana Sousa da Conceicão }}{ }^{1}$; Heiddy Marquez Alvarez²; Ivan Martins Barreto ${ }^{3}$ \\ 1. Ariana Sousa da Conceição, Graduando em licenciatura em química, Universidade Estadual de Feira de Santana, \\ e-mail: arianasousa0077@hotmail.com \\ 2. Heiddy Marquez Alvarez, DEXA, Universidade Estadual de Feira de Santana, e-mail:marquezheiddy@gmail.com \\ 3. Ivan Martins Barreto, DEXA, Universidade Estadual de Feira de Santana, e-mail: ivanmarttins@yahoo.com.br
}

PALAVRAS-CHAVE: peroxidase, suporte híbrido e imobilização enzimática.

\section{INTRODUÇÃO}

A imobilização de enzimas em suportes híbridos mesoporosos (orgânico e inorgânico) possui um grande potencial devido a que apresenta melhores características, quando comparadas a enzima livre. A síntese destes suportes pode ser feita pelo método de cocondensação a partir da utilização de aditivo inorgânico- tetraetil ortosliciato(TEOS) e como aditivo orgânico o amido, na presença de ácido clorídrico à temperatura entre 80$95^{\circ} \mathrm{C}$.

O amido é um polissacarídeo de origem vegetal, biodegradável, biocompatível cujo não apresenta toxidade. Ele é constituído por polímeros de amilase e de amilopectina, unidos por ligações glicosídicas alfa da glicose. Por suas características químicas, bem como fácil de obtenção, o amido é utilizado em indústrias alimentícias como espessante, e na indústria farmacêutica como aglutinante nos processos de granulação, como diluente, desintegrante, entre outros. O mesmo pode ser quimicamente modificado através de derivações, como a reticulação, a eterificação, a esterificação e o enxerto de grupos funcionas em sua estrutura. (SAKEER et al., 2017)

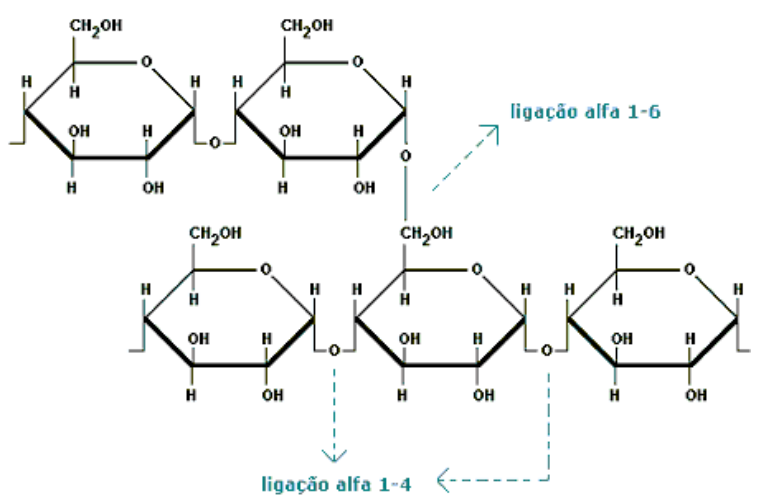

Figura 1. Estrutura do amido.

A estrutura química do amido facilita a obtenção de suportes híbridos insolúveis que sirvam para imobilizar enzimas. Uma das técnicas mais utilizadas no processo de imobilização de enzimas é a adsorção física. Este método se baseia na bioafinidade enzima-suporte, figura 2.

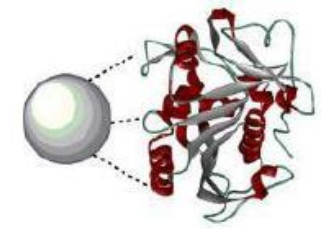

Figura 2. Imobilização por adsorção física, modificado de (SINGH et al., 2013).

Segundo Singh e colaboradores o método por adsorção física pode reduzir ou evitar a lixiviação da enzima. A enzima pode-se ligar ao suporte orgânico ou inorgânico através de interações adicionais covalentes ou não covalentes, o que ocasiona na diminuição da flexibilidade 
estrutural da enzima e uma maior rigidez a enzima imobilizada, reduzindo a possibilidade de desnaturação (SINGH et al., 2013).

\section{MATERIAL E MÉTODOS OU METODOLOGIA: \\ MATERIAL:}

Enzima peroxidase da TOYOBO, guaiacol, tetraetoxisilano (TEOS) amido comercial, solventes de interesse se encontram no LAPRON e foram adquiridos da Sigma-Aldrich (Aldrich, Milwaukee, WI, USA). Fosfato de sódio (Na2HPO4.2H2O), hidróxido de sódio $(\mathrm{NaOH})$, peróxido de hidrogênio $30 \%$ (solução aquosa) (Vetec Química, RJ, Brasil).

\section{METODOLOGIA:}

\section{Síntese de suportes híbridos de sílica:}

O processo da síntese dos suportes híbridos silicato-amido comercial, foi baseado na metodologia descrita por Álvarez et. al. (2017) com algumas modificações. Nos quais serão gerados suportes híbridos com diferentes massas de amido comercial $(1,0 \mathrm{~g} ; 0,5 \mathrm{~g}$ e $0,1 \mathrm{~g}$ ). Esse aditivo orgânico será dissolvido em $30 \mathrm{~mL}$ de água destilada, logo apos adicionará 1,7 mL de ácido clorídrico concentrado $(\mathrm{HCl}, 36 \%)$ e 5,0 mL de tetraetilortossilicato (TEOS). todo esse material será depositado em um balão de fundo redondo acoplado a um condensador de refluxo, durante 24 horas sendo aquecida por um banho de silicone entre 80 a $95^{\circ} \mathrm{C}$, depois desse periodo será resfriado em um banho de gelo, filtrado numa bomba a vacuo, lavado até atingir o $\mathrm{pH}$ neutro, secado, tritrado e armazenado, o filtrado foi guardado para ser quantificado.

\section{Determinação do percentual de glicose residual.}

A quantidade de monossacarídeo residual foi determinada pelo método Lane e Eynon, que consiste na redução dos íons cobre (II) presentes em uma solução alcalina.

\section{Imobilização da peroxidase por Adsorção física (AF):}

Se pesará $0,1 \mathrm{~g}$ do suporte, logo em seguida se adicionará $1 \mathrm{~mL}$ do tampão fosfato de sódio $\mathrm{pH} 7,0$. E várias concentrações da enzima peroxidase da TOYOBO $(0,1 \mathrm{mg} / \mathrm{mL}$; $0,2 \mathrm{mg} / \mathrm{mL}$ e $0,3 \mathrm{mg} / \mathrm{mL}$ ). Eles serão levados a agitação por 3 horas a $30^{\circ} \mathrm{C}$. Logo após será armazenado a $4{ }^{\circ} \mathrm{C}$ em condição estática, durante 24 horas. Finalmente, o biocatalisador imobilizado vai ser filtrado e lavado com tampão retirando as enzimas não adsorvidas e o filtrado reservado para quantificação da atividade enzimática.

\section{Caracterização do suporte de imobilização:}

Os suportes foram caracterizados por técnica de técnicas de Infravermelho (FT-IR) e Análise Termogravimétrica (TGA).

\section{RESULTADOS E/OU DISCUSSÃO:}

A enzima foi extraída das raízes do rabanete apresentou baixa atividade, por isso resolveu utilizar a peroxidase de raiz forte - HRP da empresa TOYOBO. 
Na figura 3. Representa a síntese do suporte híbrido TEOS-Amido.

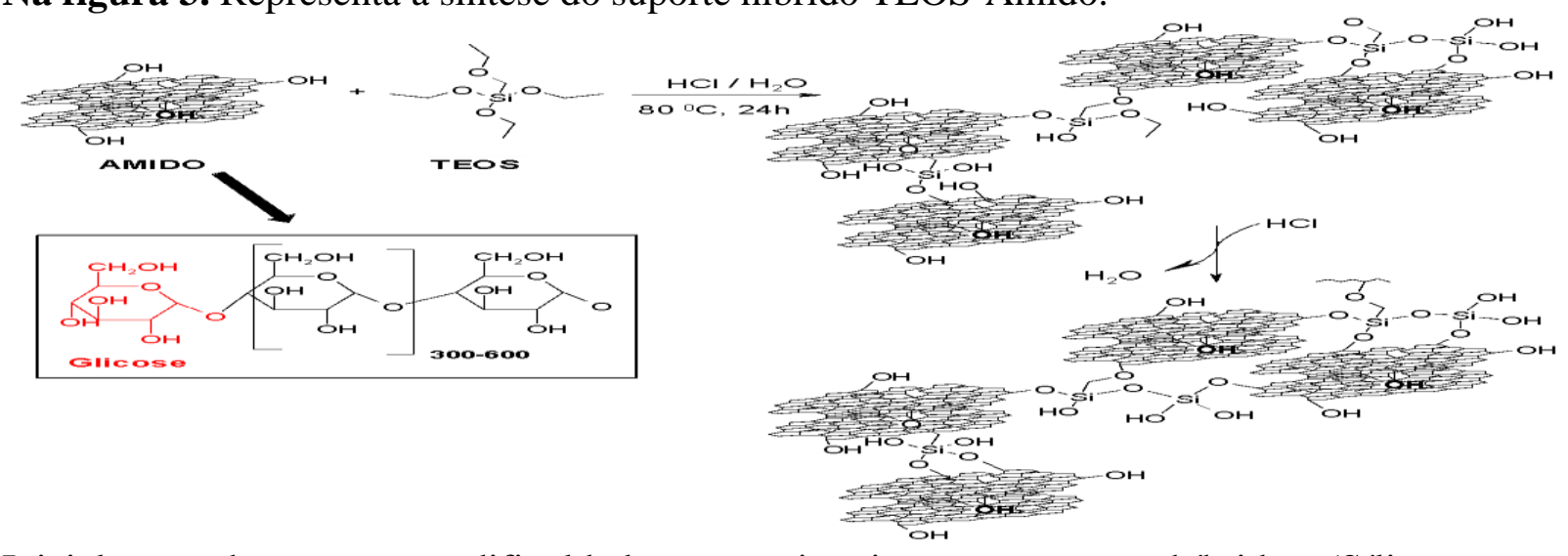

Inicialmente houve certas dificuldades para sintetizar os suportes híbridos (SílicaAmido comercial), devido à variação de temperatura. Que por sua vez, pode ultrapassar dos $95{ }^{\circ} \mathrm{C}$. Um aumento brusco da temperatura ocasiona a hidrólise do polissacarídeo (amido) em unidades de glicose que posteriormente em meio ácido degradam a ácido lelulílico e ácido fórmico, figura 2. Após várias tentativas de controle da temperatura foi possível obter bons resultados na síntese do suporte.
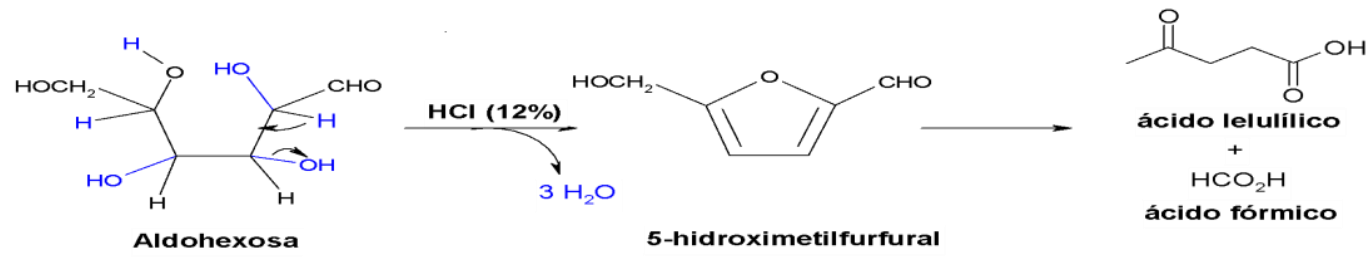

Figura 4. Degradação de glicose em meio ácido.

O processo da síntese dos suportes híbridos silicato-amido comercial, foi baseado na metodologia descrita por Álvarez et. al. (2017) com algumas modificações.

Os suportes gerados possuíam a coloração branco/ transparente (anexos 7 -9) isto condiz com o que está descrito na literatura (BARRETO 2018). Uma cor branca no suporte indica que não teve processo de polimerização-degradação do polissacarídeo.

A quantidade de glicose residual foi determinada pelo método Lane e Eynon. A reação consiste na redução dos íons cobre (II) a cobre (I) presentes em uma solução alcalina pela ação da glicose que é uma aldohexosa redutora.

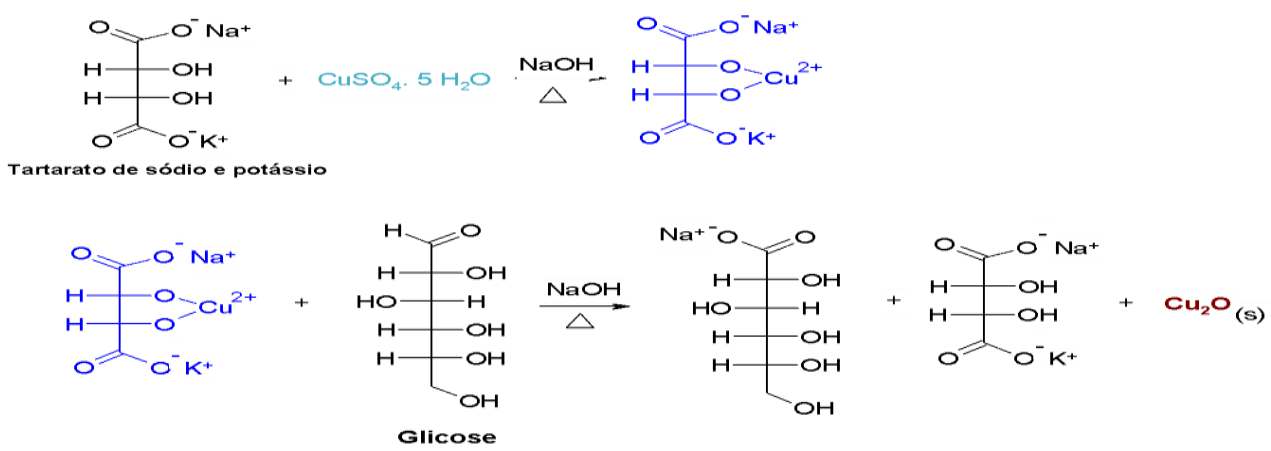

Figura 5: Reação envolvida no método de Lane e Eynon.

Na tabela 1 se apresentam os resultados obtidos a quantidade de glicose residual presente nas águas do filtrado da síntese dos diferentes suportes híbridos. 
Tabela 1. Quantificação da massa do suporte híbrido e do \% de glicose residual

\begin{tabular}{|c|c|c|c|}
\hline Suporte & Massa do amido (g) & $\%$ glicose & $\begin{array}{c}\text { Massa de suporte obtida } \\
\text { (g) }\end{array}$ \\
\hline \multirow{2}{*}{ Amido A } & \multirow{2}{*}{1,0} & 64,9 & 1,8092 \\
\hline & & 62,1 & 1,7729 \\
\hline \multirow{2}{*}{ Amido B } & \multirow{2}{*}{0,5} & 46,3 & 1,898 \\
\hline & & 45,8 & 1,8293 \\
\hline \multirow{2}{*}{ Amido C } & \multirow{2}{*}{0,1} & 31,2 & 1,4673 \\
\hline & & 22,9 & 1,3721 \\
\hline
\end{tabular}

Na tabela 1 podemos observar que a quantidade de amido comercial não influencia na massa do suporte. Em relação \% glicose redutor residual, observa-se que para 1,0 g do amido comercial, obteve aproximadamente em média $63 \%$ de glicose residual. Na medida que vai diminuindo a quantidade do amido utilizado na formação dos suportes híbridos diminui também a percentagem de glicose residual. Sendo que para 0,5 g de amido se encontra a média de $46 \%$ e para $0,1 \mathrm{~g}$ de amido teremos $27 \%$ de glicose residual. Todavia analisando os valores encontrados é notável que é melhor utilizar menor massa de amido para que não ocorra perda da matéria prima, uma vez que, não existe uma variação significativa na quantidade do material sintetizado.

\section{Imobilização da HRP}

Foi realizado a imobilização dos três suportes utilizando $0,1 \mathrm{~g}$ do mesmo e várias concentrações da enzima peroxidase da TOYOBO $(0,1 \mathrm{mg} / \mathrm{mL} ; 0,2 \mathrm{mg} / \mathrm{mL}$ e $0,3 \mathrm{mg} / \mathrm{mL})$. No momento em que se foi fazer a análise espectrofotométrica para calcular a eficiência de imobilização verificou-se valores negativos nas absorbâncias, no que indica que houve erros na manipulação ou do preparo de alguma das soluções, portanto essa parte do experimento terá que ser refeita.

\section{CONSIDERAÇÕES FINAIS:}

Foram sintetizados 3 suportes com diferentes quantidades de amido comercial $(1,0 \mathrm{~g}$; $0,5 \mathrm{~g} ; 0,1 \mathrm{~g}$ ), mantendo a mesma quantidade de TEOS (aditivo inorgânico).

A quantidade de amido comercial, não interferiu na massa gerada do produto final (suporte híbrido).

Não foi possível determinar a eficiência da atividade enzimática peroxidasica que serão refeitas.

\section{REFERÊNCIAS:}

- ADAM, F.; APPATURI, J. N.; IQBAL, A. The utilization of rice husk silica as a catalyst:Review and recent progress, Catalysis Today, 2012.

- SAKEER, K; SCORZA, T.; ROMERO, H.; ISPAS-SZABO, P.; MATEESCU, M. A. Starch materials as biocompatible supports and procedure for fastseparation of macrophages. Carbohydrate Polymers.163, p. 108-117, 2017.

- SINGH, V.; SINGH, S.K.;PANDEY, S.; KUMAR, P.Sol-gel synthesis and characterization of adsorbent and photoluminescent nanocomposites of starch and sílica. Journal of Non-Crystalline Solids. 2011. 